\title{
Silent onset of postmenopausal endometriosis in a woman with renal failure in hormone replacement therapy: a case report
}

\author{
Ugo Indraccolo ${ }^{1,2,3^{*}}$, Fabrizio Barbieri ${ }^{1,4}$
}

\begin{abstract}
Introduction: Postmenopausal endometriosis is a rare form of a common disease, since the absence of estrogenic hormone production should halt disease progression.

Case presentation: We present the case of a 54-year-old Italian Caucasian woman in surgical menopause with a history of ovarian endometriosis, who underwent voluntary hormone replacement therapy for seven years. She developed postrenal renal failure due to bilateral compression of the pelvic ureteral tract caused by two large, deeply infiltrating endometriotic nodules with no pelvic pain. She underwent operative laparoscopy with adhesiolysis of enteroenteric adhesions and excision of the endometriotic nodules encompassing the juxtavesical tract of the ureters, without obtaining improvement of renal failure.
\end{abstract}

Conclusion: Postmenopausal endometriosis can manifest itself in an unpredictable and potentially very serious manner. It is therefore important to carefully evaluate the risks and benefits of administering hormone replacement therapy to patients with previous endometriosis.

\section{Introduction}

Postmenopausal endometriosis is a rare form of a common disease, given that the absence of estrogenic hormone production should halt disease progression [1]. Oxholm et al [2] reported that two to five percent of endometriosis is diagnosed after menopause. It has been reported that endometriosis may develop essentially in women undergoing hormone replacement therapy [2] with some exceptions [3], indicating the possibility that in some cases endometriosis may be completely independent of gonadic estrogens. Whether postmenopausal endometriosis is due to exogenous estrogens or presumably independent of gonadic estrogens, the silent growth of the disease can result in potentially serious and unpredictable complications. For example, it may grow without the typical symptoms such as catamenial pain and may involve the ureters [4,5] or bowel [6], producing complications such as renal failure or intestinal

\footnotetext{
* Correspondence: ugo.indraccolo@libero.it

${ }^{1}$ Maternal-Child Department, Operative Unit of Obstetrics and Gynecology, ULSS 17 - Veneto, Monselice (PD), Italy

Full list of author information is available at the end of the article
}

obstruction. The following case explains the onset of postmenopausal endometriosis with renal failure.

\section{Case presentation}

A 54-year-old Italian Caucasian woman, weighing $71 \mathrm{~kg}$ and with a height of $160 \mathrm{~cm}$, was admitted to our facility in order to have a laparoscopic removal of two nodules compressing both ureters. She had received diagnosis of endometriosis laparoscopically, when she was 43. At 44 years of age, she underwent a total laparotomic hysterectomy with bilateral adnexectomy for metrorrhagia from uterine fibromatosis. During the operation and after pathological examination, no sign of endometriosis was found. Subsequently, she underwent voluntary hormone replacement therapy (estrogen-based only) for seven years with good general health until the detection, during the eighth year of menopause, of renal failure due to bilateral hydronephrosis (detected via MRI). The bilateral hydronephrosis was induced by extrinsic compression of both ureters (at supravesical fossa) by nodules compatible with deeply infiltrating endometriosis. S-Ca 125 appeared within the norm (normal values are considered below $31 \mathrm{microU} / \mathrm{ml}$ ) and no 
pelvic pain was reported. Upon hospitalization, five months after instrumental diagnosis and following subsequent ureteral stenting, her creatinine value was 1.71 $\mathrm{mg} / \mathrm{dl}$ (range 0.66 to $1.09 \mathrm{mg} / \mathrm{dl}$ ), with blood urea nitrogen at $57 \mathrm{mg} / \mathrm{dl}$ (range 17 to $43 \mathrm{mg} / \mathrm{dl}$ ). S-Ca 125 again appeared to be within the normal range (below 31 $\mathrm{microU} / \mathrm{ml}$ ). She then underwent operative laparoscopy with adhesiolysis of entero-enteric adhesions and excision of endometriotic nodules encompassing the juxtavesical tract of the ureters: on the right extending to the external iliac artery and obturator foramen and on the left, to the rectum. Pathological examination of the excised nodules confirmed the instrumental and laparoscopic diagnosis of postmenopausal endometriosis. Post-operative recovery was complicated by bronchopneumonia. After hospital discharge, creatinine value was $1.56 \mathrm{mg} / \mathrm{dl}$ (range 0.66 to $1.09 \mathrm{mg} / \mathrm{dl}$ ) with thinning of the right renal cortex which suggested mild renal failure. Following removal of the ureteral stents three months after surgery, the patient appeared to be in good health despite the mild renal failure.

\section{Discussion}

For more than 10 years it has been acknowledged $[7,8]$ that endometriosis can express aromatase activity, particularly during tissue inflammation. In a recent review, Attar and Bulun [9] illustrate how endometriosis can express various enzymes from the biosynthetic pathway of steroid hormones: estrogen production is caused by aromatase activity during inflammatory episodes; in addition, estrogen production can increase inflammation of endometriotic tissue. During menopause it is plausible that endometriosis can grow independently of gonadic estrogens due to the renewed synthesis of estrogens in the endometriotic nodule. Therefore, the effect of estrogens may be variable overall, because inflammation affects estrogen production in the nodule. In addition, Rosa-e-Silva et al [3] proposed that obesity may have a particular role in the growth of post-menopausal endometriosis due to estrogen production by fatty tissue. Oxholm et al [2] have recently reviewed cases of postmenopausal endometriosis, pointing out that the majority of postmenopausal endometriosis is detected in patients undergoing hormone replacement therapy, particularly when only estrogen-based. In addition, the onset of endometriosis during menopause appears to be more probable following physiological menopause, suggesting that the ovaries may have a certain role in the disease even in the post-menopausal phase. The authors [2] conclude that it is debatable overall whether hormone replacement therapy can favor the growth of endometriosis, implying, however, that this is possible in some cases and that endometriosis should be taken into consideration in menopausal patients presenting the pain symptoms typical of the disease.

\section{Conclusion}

Even in fertile patients, endometriosis shows varying biological behavior, with variable clinical symptoms and outcomes in relation to hormonal status. However, it is very difficult for a clinician to ascertain silent endometriosis post-menopause, when estrogen production is lacking. In light of this case and of the varying biological behavior of endometriosis, clinicians must certainly keep in mind that postmenopausal endometriosis can appear in an atypical manner and could go undetected, leading to serious complications. This event may occur particularly in patients with a type of hormonal trigger that could aggravate inflammatory stress. Therefore, we recommend a careful evaluation of whether or not to prescribe hormone replacement therapy to patients in menopause with previously ascertained endometriosis.

\section{Patient perspective}

The patient was not happy about her experience and considers endometriosis a painful disease that she had hoped would be cured with her hysterectomy with adnexectomy. She hopes that the description of her experience will be helpful in preventing and treating the troubles that such a disease can provoke.

\section{Consent}

Written informed consent was obtained from the patient for publication of this case report. A copy of the written consent is available for review by the Editor-in-Chief of this journal.

\section{Abbreviations}

dl: deciliter; mg: milligram; microU: micro-unit; ml: milliliter; MRI: magnetic resonance imaging; S-Ca 125: serum Ca-125

\section{Author details}

${ }^{1}$ Maternal-Child Department, Operative Unit of Obstetrics and Gynecology, ULSS 17 - Veneto, Monselice (PD), Italy. ${ }^{2}$ Department of Surgical Sciences, Institute of Obstetrics and Gynecology, University of Foggia, Foggia, Italy. ${ }^{3}$ Via Montagnano 16, 62032 Camerino (MC), Italy.Tel: 393286180677, Fax: 390737 636668. ${ }^{4}$ Dipartimento materno infantile, U.O. di Ostetricia e Ginecologia, Ospedale di Monselice, Via Marconi 19, 35043 Monselice (PD), Italy.

\section{Authors' contributions}

UI collected the bibliography, read it and was the major contributor in writing the article. FB performed laparoscopic debulking of deep infiltrating endometriosis. Both authors have read and approved the final manuscript.

\section{Competing interests}

The authors declare that they have no competing interests.

Received: 29 September 2009 Accepted: 4 August 2010

Published: 4 August 2010 


\section{References}

1. Bulun SE: Endometriosis. N Engl J Med 2009, 360:268-279.

2. Oxholm D, Knudsen UB, Kryger-Baggesen N, Ravn P: Postmenopausal endometriosis. Acta Obstet Gynecol Scand 2007, 86:1158-1164.

3. Rosa-e-Silva JC, Carvalho BR, Barbosa Hde F, Poli-Neto OB, Rosa-e-Silva AC, Candido-dos-Reis FJ, Nogueira AA: Endometriosis in postmenopausal women without previous hormonal therapy: report of three cases. Climateric 2008, 11:525-528.

4. Al-Khawaja M, Tan PH, MacLennan GT, Lopez-Beltran A, Montironi R, Cheng L: Ureteral endometriosis: clinicopathological and immunohistochemical study of 7 cases. Hum Pathol 2008, 39:954-959.

5. Khong SY, Lam A, Coombes G, Ford S: Surgical management of recurrent ureteric endometriosis causing recurrent hypertension in a postmenopausal woman. J Minim Invasive Gynecol 2010, 17:100-103.

6. Popoutchi P, dos Reis Lemos CR, Silva JC, Nogueira AA, Feres O, Ribeiro da Rocha JJ: Postmenopausal intestinal obstructive endometriosis: case report and review of the literature. Sao Paolo Med J 2008, 126:190-193.

7. Noble LS, Simpson ER, Johns A, Bulun SE: Aromatase expression in endometriosis. J Clin Endocrinol Metab 1996, 81:174-179.

8. Noble LS, Takayama K, Putman JM, Johns DA, Hinshelwood MM, Agarwal VR, Zhao Y, Carr BR, Bulun SE: Prostaglandin E2 stimulates aromatase expression in endometriosis-derived stromal cells. J Clin Endocrinol Metab 1997, 82:600-606.

9. Attar E, Bulun SE: Aromatase and other steroidogenic genes in endometriosis: translational aspects. Hum Reprod Update 2006, 12:49-56.

doi:10.1186/1752-1947-4-248

Cite this article as: Indraccolo and Barbieri : Silent onset of

postmenopausal endometriosis in a woman with renal failure in

hormone replacement therapy: a case report. Journal of Medical Case

Reports 2010 4:248.

\section{Submit your next manuscript to BioMed Central and take full advantage of:}

- Convenient online submission

- Thorough peer review

- No space constraints or color figure charges

- Immediate publication on acceptance

- Inclusion in PubMed, CAS, Scopus and Google Scholar

- Research which is freely available for redistribution

Submit your manuscript at www.biomedcentral.com/submit 